\title{
Clozapine-carboxylic acid plasticized co-amorphous dispersions: Preparation, characterization and solution stability evaluation
}

\author{
AHMED MAHMOUD ABDELHALEEM ALI ${ }^{1,2 *}$ \\ ADEL AHMED ALI ${ }^{1}$ \\ IBRAHIM ABDULLAH MAGHRABI ${ }^{2}$ \\ ${ }^{1}$ Department of Pharmaceutics \\ Faculty of Pharmacy \\ Beni Suef University, Egypt \\ ${ }^{2}$ Department of Clinical Pharmacy \\ Faculty of Pharmacy \\ Taif University \\ Kingdom Saudi Arabia
}

\begin{abstract}
This study addressed the possibility of forming of co-amorphous systems between clozapine (CZ) and various carboxylic acid plasticizers (CAPs). The aim was to improve the solubility and oral bioavailability of clozapine. Co-amorphous dispersions were prepared using modified solvent evaporation methodology at drug/plasticizer stoichiometric ratios of 1:1, 1:1.5 and 1:2. Solid state characterization was performed using differential scanning calorimetry, X-ray diffraction and infra red spectroscopy. Highly soluble homogeneous co-amorphous dispersions were formed between clozapine and CAPs via hydrogen bonding. The co-amorphous dispersions formed with tartaric acid (1:2) showed the highest dissolution percentage (> $95 \%$ in 20 minutes) compared to pure crystalline CZ (56\%). Highly stable solutions were obtained from co-amorphous CZ-citric and CZ-tartaric acid at 1:1.5 molar ratio. The prepared dispersions suggest the possibility of peroral or sublingual administration of highly soluble clozapine at a reduced dose with the great chance to bypass the first pass metabolism.
\end{abstract}

Keywords: clozapine, carboxylic acids, co-amorphous systems, plasticizer

Clozapine is one of the potent antipsychotic drugs that have been used in the treatment of schizophrenia (1). The drug has a biological half-life of $6.5 \pm 1.5 \mathrm{~h}$ and undergoes extreme first-pass metabolism after oral administration; its bioavailability ranges from $27-50 \%$ of the ingested dose $(2,3)$. Clozapine has low water solubility, being soluble only in acidic solutions, and hence improvement of its water solubility will enable reduction of oral dosing and help in overcoming the side effects, which include weight gain, induced fever and agranulocytosis (4). Bypassing the first-pass metabolism can be achieved by using oral dosage forms such as buccal fast dissolving or sublingual tablets (5). Various attempts were made to improve its bioavailability by using co-amorphous lipid nanoparticles for oral administration (6) or to formulate clozapine into sustained release formulations using cross-linked chitosan microparticles (7). Co-amorphous dispersions and co-

\footnotetext{
*Correspondence; e-mail: ahmed.abdelhalem@pharm.bsu.edu.eg, ahmed.mahmoud3@yahoo.com
} 
crystals are recent and highly effective approaches used to improve water solubility and bioavailability of poorly soluble crystalline drugs (8). Although these two systems are different in shape, they are commonly known as multi-component dispersions composed of an active ingredient with one or more neutral molecules known as co-formers $(9,10)$. However, co-crystallization often needs sophisticated methods for preparation and quantification, in addition to physical instability and possible formation of polymorphs and hydrates. Amorphous solids are non-crystalline materials, in which the arrangement of the component atoms does not have a long-range order. They are also considered suitable and easy alternatives to co-crystals and provide higher dissolution rates (11). Co-amorphous dispersions can be prepared from solutions of crystalline drugs, especially when rapid co-precipitation is pursued using carboxylic acids as plasticizing agents $(12,13)$. Stable coamorphous systems have been prepared from low solubility drugs and small molecular mass amino acids (14) or neutral molecules capable of forming strong $\mathrm{H}$-bonding such as saccharin (15) or nicotinamide (16). Although numerous successful plasticized formulations have been prepared using carboxylic acids (17-20), plasticized co-amorphous dispersions prepared from crystalline drugs with polycarboxylic acids are rare. Moreover, no studies have addressed the use of carboxylic acid plasticizers (CAPs) in amorphization of solid crystalline drugs by employing solvent evaporation under vacuum as the method of preparation. Therefore, in this research, preparation of stable clozapine co-amorphous dispersions by evaporation under vacuum was addressed in an attempt to enhance the drug water solubility, bioavailability and to enable reduced dosing.

\section{EXPERIMENTAL}

\section{Materials}

Clozapine was obtained as a free sample from the Egyptian Pharmaceutical Industries Company (EPICO, Egypt). Anhydrous carboxylic acids, tartaric, citric and oxalic acid, were purchased from El Nasr, Chemical and Pharmaceutical Company (Egypt). Ethanol (95\%) was purchased from El-Gomhoria Company (Egypt). Methanol HPLC grade was purchased from Sigma Aldrich (UK). Triethanolamine was purchased from BDH Prolabo (UK). Other chemicals were of analytical grade and were used as obtained.

\section{Preparation of clozapine/carboxylic acid co-amorphous dispersions}

Solvent evaporation under vacuum was adopted as the method for preparation of co-amorphous systems in a modification of the slow solvent evaporation method usually used for crystallization (where fast evaporation under vacuum with little heat is used instead of slow evaporation at room temperature) (21). Weighted amounts of clozapine (150 mg) and calculated equivalent amounts of anhydrous CAPs, citric, D-tartaric or oxalic acid (chemical structures given in Fig. 1), at the selected molar ratios (Table I), were dissolved in 20 $\mathrm{mL}$ ethanol (95\%) and then placed in a rotary evaporation flask. The selected acids had low molecular mass and low glass transition temperature and were expected to help amorphization of clozapine via lowering of its glass transition temperature. Since polycarboxylic acids undergo intra- and inter-molecular interactions (H-bonding), this could also happen with drugs with donor and acceptor nitrogen atoms such as clozapine, especially during rapid co-precipitation with one of the acids under vacuum from an alcoholic solu- 


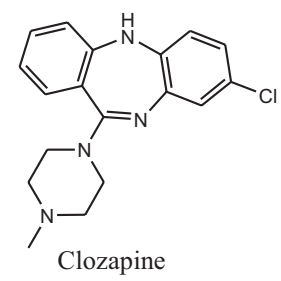<smiles>O=C(O)CC(O)(CC(=O)O)C(=O)O</smiles>

Citric acid<smiles>O=C(O)C(=O)O</smiles>

Oxalic acid<smiles>O=C(O)C(O)C(O)C(=O)O</smiles>

Tartaric acid

Fig. 1. Chemical structure of clozapine and polycarboxylic acid plasticizers.

Table I. Composition of clozapine-carboxylic acid co-amorphous dispersions

\begin{tabular}{cccccc}
\hline Formulation & Clozapine $(\mathrm{mg})$ Citric acid $(\mathrm{mg})$ & $\begin{array}{c}\text { Tartaric acid } \\
(\mathrm{mg})\end{array}$ & $\begin{array}{c}\text { Oxalic acid } \\
(\mathrm{mg})\end{array}$ & $\begin{array}{c}\text { Stoichiometric } \\
\text { ratio }\end{array}$ \\
\hline$M_{\mathrm{r}}$ & 306.80 & 192.12 & 150.09 & 90.03 & - \\
F1 & 150 & 94.50 & - & - & $1.0: 1.0$ \\
F2 & 150 & 141.75 & - & - & $1.0: 1.5$ \\
F3 & 150 & 189.00 & - & - & $1.0: 2.0$ \\
F4 & 150 & - & 73.50 & - & $1.0: 1.0$ \\
F5 & 150 & - & 110.25 & - & $1.0: 1.5$ \\
F6 & 150 & - & 147 & - & $1.0: 2.0$ \\
F7 & 150 & - & - & 43.50 & $1.0: 1.0$ \\
F8 & 150 & - & - & 65.25 & $1.0: 1.5$ \\
F9 & 150 & - & - & 87.00 & $1.0: 2.0$ \\
\hline
\end{tabular}

tion. The flask contents were then subjected to sonication for $10 \mathrm{~min}$ in a water bath sonicator (Ultrasonic Cleaner Model 57 H, Ney Instruments Co. Ltd, USA) until all contents were completely dissolved. The resulting solution was evaporated under vacuum $(0.239 \mathrm{MPa})$ using a rotary evaporator (Barloworld Scientific Ltd., UK). The water bath temperature was kept at 45 ${ }^{\circ} \mathrm{C}$. Upon complete dryness, the collected mass was pulverized and passed through a number 60 sieve $(250 \mu \mathrm{m}$ apertures), and then kept in a desiccator until further use.

\section{Scanning electron microscopy (SEM)}

The morphology of prepared dispersions was examined using scanning electron microscopy (Analytical Scanning Microscope, JEOL-JSM-6510LA, JEOL, Japan). Few specks from each formulation were placed on the carbon stubs and then coated using a gold sputter (SPI-Module Sputter Coater, SPI Supplies Inc., USA), followed by microscopical scanning. 


\section{Differential scanning calorimetry (DSC)}

Samples of pure clozapine, CAPs and the prepared co-amorphous dispersion formulations (5 mg each) were individually filled into aluminium flat-bottomed pans and heated in a DSC-60 instrument (Shimadzu, Japan) in nitrogen atmosphere. The heating temperature used for the crystalline components was set between 20 and $300^{\circ} \mathrm{C}$ with a heating rate

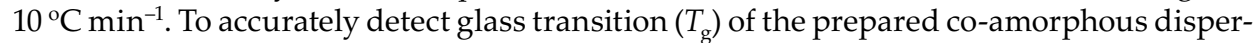
sions, another heating range was selected $\left(-40\right.$ to $\left.300^{\circ} \mathrm{C}\right)$. Comparisons were made with amorphous clozapine prepared by melting at $190{ }^{\circ} \mathrm{C}$, followed by quench cooling under liquid nitrogen (14).

\section{$X$-ray powder diffraction $(X R P D)$}

Samples of clozapine powder, CAPs as well as solid dispersion formulations were subject to X-ray diffraction analysis. A Shimadzu XRD-6000 X-ray powder diffractometer (Shimadzu, Japan) coupled with a standard Cu sealed X-ray tube with voltage, and current (40 $\mathrm{kV}$ and $40 \mathrm{~mA}$ ), was used to characterize the amorphous or crystalline state of formulations (22). Data collection was performed at 2-theta of 5-60 in steps of 0.04 and scanning speed of 0.4 per step. Any change in the crystalline pattern of the prepared co-amorphous dispersions compared to those of the parent crystalline components was recorded and evaluated.

\section{Fourier transform infra-red analysis (FTIR)}

Small samples (2-3 mg) of clozapine, coformers and prepared dispersions were individually mixed with $500 \mathrm{mg}$ of dry potassium bromide. Powder mixtures were compressed into discs under a pressure of 68.5-103.4 MPa using a hydrostatic press. The infrared spectrum was determined in a scanning range of $400-4000 \mathrm{~cm}^{-1}$ using a Fourier transform infra red instrument (Thermo Scientific Nicolet 6700, USA).

\section{Drug content evaluation}

Samples of the prepared amorphous dispersions equivalent to $5 \mathrm{mg}$ clozapine were dissolved in distilled water and adjusted to volume using a standard 50-mL volumetric flask. Then, $2 \mathrm{~mL}$ were taken and diluted to $10 \mathrm{~mL}$ with the mobile phase. Drug content was then determined using the HPLC system composed of an isocratic pump (Model LC10 As, Shimadzu), C18 column $(3.9 \times 150 \mathrm{~mm}$ BondaPack $10 \mu \mathrm{m}$, Waters Chromatography, USA) and an ultraviolet wavelength detector (Model SpD-10 A, Shimadzu). The mobile phase consisted of methanol/water (78:22) with $0.5 \%, V / V$, triethanolamine. The detection wavelength was set at $254 \mathrm{~nm}$ and the flow rate at $1 \mathrm{~mL} \mathrm{~min}^{-1}(23)$.

\section{In vitro dissolution studies}

Dissolution of clozapine from the prepared co-amorphous dispersions was evaluated and compared to that of pure crystalline clozapine. An amount equivalent to $10 \mathrm{mg}$ clozapine from each formulation was compressed into tablets using lactose monohydrate as a filler. Tablets weighing $100 \mathrm{mg}$ each were compressed using a single punch machine with convex 5-mm punch and die set (single punch tablet press, model TDP, Triowin Lab Tech. 
Co. Ltd., China). The compression step using lactose was necessary to differentiate between formulations due to immediate (flash) dissolution of the powder formulations once sprinkled into the dissolution medium and to temporarily protect hygroscopic formulations from adherence to the die if compressed alone. The dissolution process was carried out using a USP dissolution tester apparatus II (paddle method, SR 8 plus model, Hanson Research, USA). The dissolution medium was composed of $500 \mathrm{~mL}$ distilled water and the paddles rotated at a speed of $50 \mathrm{rpm}$ with water bath temperature kept at $37 \pm 0.5^{\circ} \mathrm{C}$. At short time intervals (5, 10, 15, 20 and $30 \mathrm{~min})$, samples were withdrawn for analysis and replaced with fresh medium.

\section{Solution stability study}

Solutions of co-amorphous dispersion formulations containing equivalent amounts to $5 \mathrm{mg}$ clozapine dissolved in $50 \mathrm{~mL}$ distilled water were prepared and stored at a temperature of $40{ }^{\circ} \mathrm{C}$ and $75 \%$ relative humidity for two weeks. This study was performed in order to assure that solutions of the prepared dispersions formed homogeneous one phase systems probably through $\mathrm{H}$-bonding interactions with improved hydration (i.e., showing clear solutions without signs of precipitation of single components). These conditions were adjusted using a controlled temperature hot air oven and a saturated salt solution (3). Solutions were investigated for their physical appearance including clarity, separation or precipitation at the end of the storage period, in addition to re-evaluation of drug content. The obtained results were compared with those pertaining to freshly prepared dispersion sample solutions.

\section{RESULTS AND DISCUSSION}

\section{Morphological characterization}

Scanning electron microscopy of the prepared dispersions indicated formation of brittle flake-like amorphous powders between clozapine and all plasticizing acids at various stoichiometric ratios (Fig. 2).

\section{Differential scanning calorimetry}

The individual DSC thermograms of crystalline clozapine, citric, D-tartaric and oxalic acids showed single characteristic endothermic melting peaks at 185, 158, 210 and 194 ${ }^{\circ} \mathrm{C}$, respectively (Table II). The thermograms physical mixtures of CZ-citric, CZ-tartaric and CZ-oxalic acid ratio at 1:1, also demonstrated separate melting peaks at lower temperatures $\left(157.23,183.42\right.$ and $142.67^{\circ} \mathrm{C}$ ), respectively, suggesting possible interactions (Table II). Thermograms of the co-amorphous dispersions F1-F3 (Fig. 3a) containing citric acid at 1, 1.5 and 2 molar ratios, respectively, showed broad peaks with no sharp melting. The appearance of single $T_{\mathrm{g}} \mathrm{s}$ at 65.21 and $114.01{ }^{\circ} \mathrm{C}$ for F2 and F3 (Table II), respectively, also suggest formation of co-amorphous phases (24). The prepared amorphous clozapine by melting and quench cooling also demonstrated a $T_{\mathrm{g}}$ at $65^{\circ} \mathrm{C}$ (Table II), whilst the dispersion F1 showed two $T_{\mathrm{g}}$ values at 11 and $68.20^{\circ} \mathrm{C}$ suggesting formation of separate amorphous components. This result correlates well with the data previously reported for clozapine, 
A. M. Abdelhaleem Ali et al.: Clozapine-carboxylic acid plasticized co-amorphous dispersions: Preparation, characterization and solution stability evaluation, Acta Pharm. 65 (2015) 133-146.
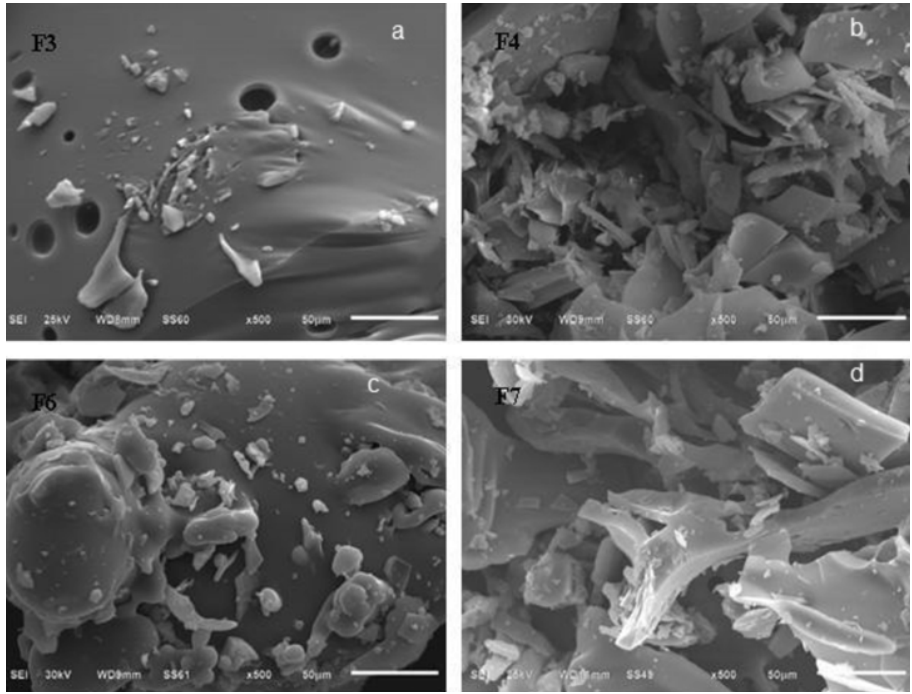

Fig. 2. Scanning electron micrographs of solid co-amorphous dispersions of clozapine with: a) citric acid F3, b) tartaric acid F4, c) tartaric acid F6 and d) oxalic acid F7.

Table II. Dissolution characteristics of clozapine co-amorphous dispersions and attributes of solution stability

\begin{tabular}{|c|c|c|c|c|c|c|c|c|}
\hline \multirow[b]{2}{*}{ Formula } & \multicolumn{2}{|c|}{ Melting point $\left({ }^{\circ} \mathrm{C}\right)$} & \multirow{2}{*}{ 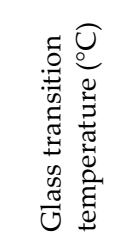 } & \multirow{2}{*}{ 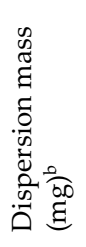 } & \multirow{2}{*}{ 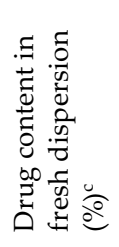 } & \multirow{2}{*}{ 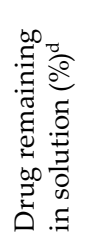 } & \multicolumn{2}{|c|}{$\begin{array}{l}\text { Percentage } \\
\text { dissolved }\end{array}$} \\
\hline & $\begin{array}{l}\text { Physical } \\
\text { mixture (1:1) }\end{array}$ & Coformer & & & & & $\begin{array}{l}\mathrm{Q}_{10} \\
(\%)^{\mathrm{e}}\end{array}$ & $\begin{array}{l}Q_{20} \\
(\%)^{\mathrm{f}}\end{array}$ \\
\hline Clozapine & - & 185 (none) & 65.0 & 5.0 & 100.0 & 99.0 & 56.8 & 67.8 \\
\hline $\mathrm{F} 1$ & 157.2 & 158 (citric) & $11.0 / 68.2$ & 8.1 & 75.5 & 75.0 & 52.5 & 77.7 \\
\hline $\mathrm{F} 2$ & - & 158 (citric) & 65.2 & 9.7 & 55.3 & 100.0 & 79.8 & 92.7 \\
\hline F3 & - & 158 (citric) & 114.0 & 11.3 & 50.2 & 90.9 & 78.5 & 85.9 \\
\hline $\mathrm{F} 4$ & 183.4 & 210 (tartaric) & $11.4 / 69.9$ & 7.4 & 76.0 & 82.7 & 80.6 & 96.1 \\
\hline F5 & - & 210 (tartaric) & 72.2 & 8.7 & 56.5 & 100.0 & 71.6 & 84.7 \\
\hline F6 & - & 210 (tartaric) & 77.7 & 9.9 & 55.9 & 95.6 & 86.9 & 96.0 \\
\hline F7 & 142.7 & 194 (oxalic) & $82.7 / 115.9$ & 6.4 & 85.4 & 96.5 & 71.0 & 90.9 \\
\hline F8 & - & 194 (oxalic) & $48.0 / 112.3$ & 7.2 & 69.6 & 93.2 & 78.0 & 97.2 \\
\hline F9 & - & 194 (oxalic) & 67.6 & 7.9 & 81.9 & 92.1 & 74.8 & 88.2 \\
\hline
\end{tabular}

${ }^{\text {a }} T_{\mathrm{g} 1}$ or $T_{\mathrm{g} 1} / T_{\mathrm{g} 2}$

${ }^{\mathrm{b}}$ Weighed amount of dispersion mass equivalent to $5 \mathrm{mg}$ clozapine.

c Percentage clozapine content in fresh samples $(n=3)$.

${ }^{\mathrm{d}}$ Percentage clozapine remaining in solution after two weeks of storage.

e, f Percentage clozapine dissolved after 10 and 20 minutes, respectively. 
which demonstrated various glass transition temperatures $\left(51,54\right.$ and $\left.64^{\circ} \mathrm{C}\right)$ in its amorphous blends with chitosan (8) and those reported for amorphous citric acid exhibiting a glass transition temperature at $11^{\circ} \mathrm{C}$ (25). The DSC thermograms of F4-F6 (containing Dtartaric acid at 1, 1.5 and 2 molar ratio, respectively) shown in Fig. 3b, also demonstrated broad peaks with complete disappearance of characteristic melting endotherms of parent components. The co-amorphous dispersion F4 demonstrated two different $T_{\mathrm{g}}$ values, however formulation F5 and F6 showed single $T_{\mathrm{g}}$ at 72.23 and $77.73^{\circ} \mathrm{C}$, respectively (Table II). The observed single $T_{\mathrm{g}} \mathrm{s}$ were quite higher than that of amorphous clozapine $\left(65^{\circ} \mathrm{C}\right)$ which indicate formation of highly stable co-amorphous dispersions. The co-amorphous dispersions F7 and F8 (containing oxalic acid at 1 and 1.5 molar ratio, respectively) showed similar broad thermograms (Fig. 3c) to those observed with CZ-citric and CZ-tartaric acid dispersions. Each of F7 and F8 exhibited two $T_{\mathrm{g}}$ temperatures representing formation of two separate amorphous phases, whilst $\mathrm{F} 9$ showed single $T_{\mathrm{g}}$ at $67.58^{\circ} \mathrm{C}$ (Table II) indicating homogenous co-amorphous system. The above results indicated that the interaction between clozapine and CAPS is possible in all proportions. However, possibility of formation of homogenous co-amorphous dispersions with single $T_{\mathrm{g}}$ values were only observed at specific molar ratios.
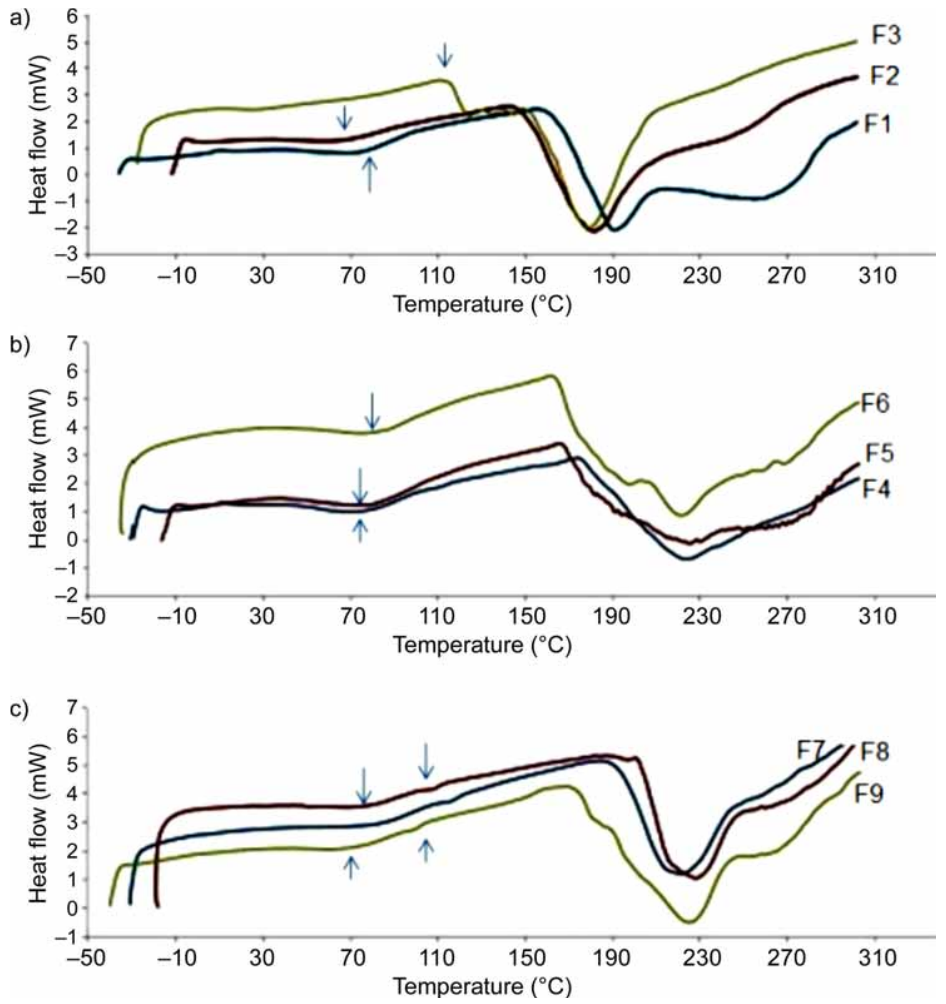

Fig. 3. DSC curves for clozapine co-amorphous dispersions with: a) citric acid (F1-F3), b) tartaric acid (F4-F6) and c) oxalic acid (F7-F9). Arrows refer to $T_{\mathrm{g}}$ points. 


\section{X-ray powder diffraction}

X-ray diffraction patterns of clozapine (Fig. 4a) demonstrated characteristic intense peaks between 2-theta 10,17, 19.5, 21 23.7, 25 and 30 , indicating a crystalline structure. These results are in good agreement with what was reported for clozapine in the literature (6). The XRD pattern for citric acid also showed multiple sharp characteristic peaks at 2-theta of 13, 14, 19, 25, 28, 32, 34, 36, 38, 42 and 58 . The XRD spectra of co-amorphous dispersions F1, F2 and F3 demonstrated disappearance of the characteristic peaks of both citric acid and clozapine and appearance of the characteristic amorphous halo. The appearance of a characteristic amorphous halo in all the co-amorphous dispersions, along with DSC data, strongly suggest that amorphous systems were obtained through H-bonding interactions between the drug and the plasticizing acid (26). Formulation F3 showed a
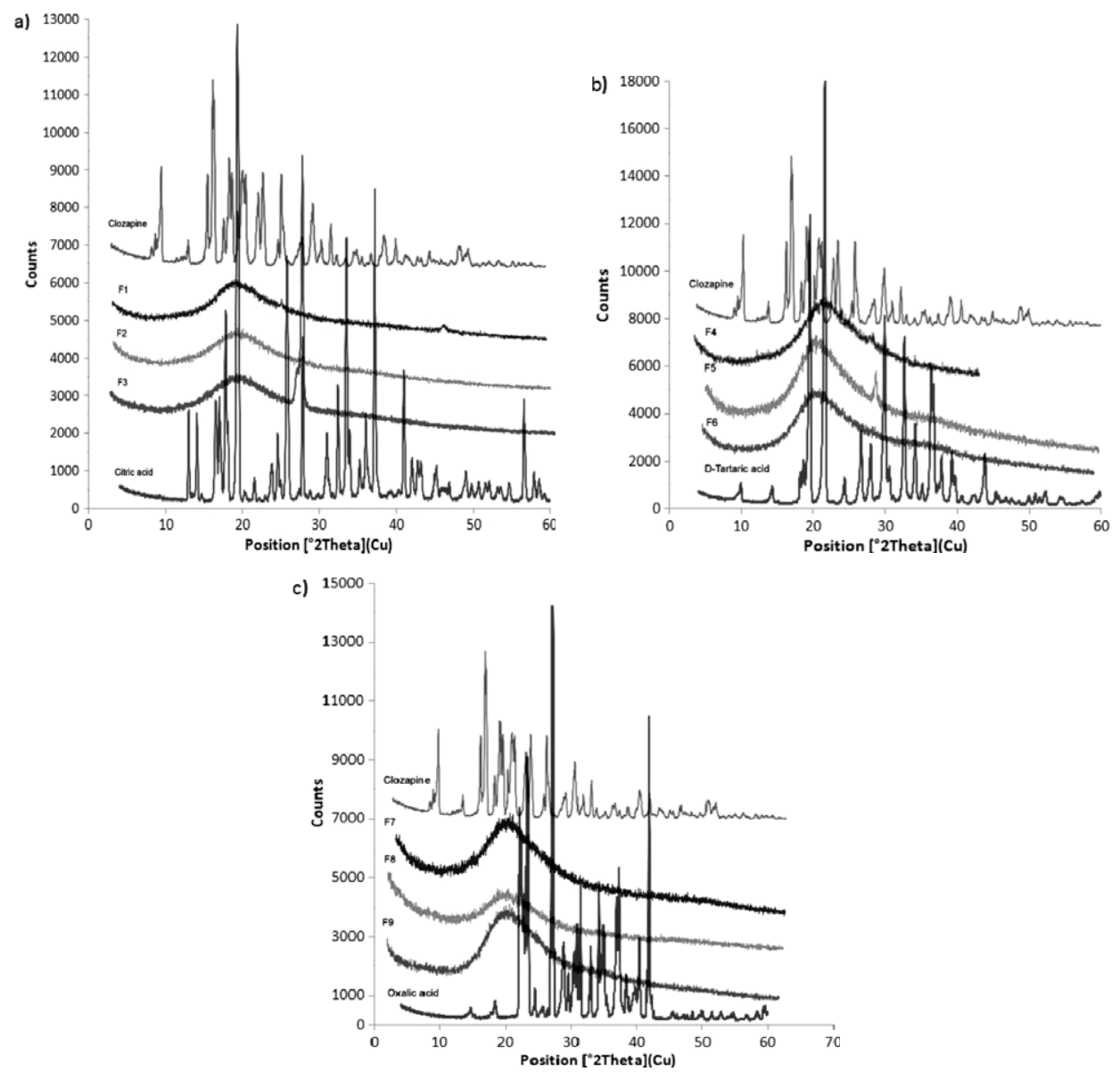

Fig. 4. XRPD patterns for: a) clozapine, citric acid and its amorphous solid dispersions F1-F3, b) clozapine, tartaric acid and its co-amorphous dispersions (F4-F6), c) clozapine, oxalic acid and its coamorphous dispersions (F7-F9). 
A. M. Abdelhaleem Ali et al.: Clozapine-carboxylic acid plasticized co-amorphous dispersions: Preparation, characterization and solution stability evaluation, Acta Pharm. 65 (2015) 133-146.

single sharp reflection at 2-theta of $28^{\circ}$, which indicates the presence of the remaining crystalline components and separation of phases (amorphous and crystalline).

The XRPD patterns for D-tartaric acid and its co-amorphous dispersions with clozapine are shown in Fig. $4 \mathrm{~b}$ and demonstrated two sharp peaks characteristic of the acid at 2-theta of 19 and $22^{\circ}$ with other multiple peaks 30-45. The XRD patterns observed for formulations F4, F5 and F6 were highly attenuated compared to those of clozapine and D-tartaric acid and the characteristic amorphous halo was also observed. Formulation F5 showed the lowest attenuation and had a new single short reflection at 2-theta of $28^{\circ}$. This latter reflection is similar to that of F3 and both suggest incomplete interactions between clozapine and the acid leaving unreacted crystalline components. Oxalic acid XRD patterns shown in Fig. 4c demonstrated characteristic peaks at 2-theta of 22, 23, 28 and $42^{\circ}$. The co-amorphous dispersions F7, F8 and F9 showed the disappearance of characteristic peaks and appearance of a broad short halo at 2-theta of $20^{\circ}$ similar to those found with citric and tartaric acid dispersions. From the observations of broad DSC thermograms with no sharp melting and the amorphous halo in XRPD patterns, it becomes obvious that amorphous dispersions rather than crystalline structures were formed (27). From these dispersion systems, co-amorphous homogenous phases were observed in F2, F5, F6 and F9. This can be also supported by investigation of the infrared spectra of parent components compared to the prepared dispersions.

\section{IR-spectral analysis}

The results of FTIR spectra for clozapine (Fig. 5a) indicated a characteristic peak at $3000-3300 \mathrm{~cm}^{-1}$, which represents the free N-H stretching of the diazepine ring and at 2921, 2789 and $2791 \mathrm{~cm}^{-1}$, representing aliphatic $\mathrm{C}-\mathrm{H}$ stretching as reported in the literature (7). The FTIR spectra of pure citric acid indicated a characteristic peak at $1705 \mathrm{~cm}^{-1}$, which was attributed to the $\mathrm{C}=\mathrm{O}$ stretching vibration in carboxyl groups. Formulations F1, F2 and F3 showed shortened peaks of clozapine ( $\mathrm{C}-\mathrm{H}$ stretching and $\mathrm{C}=\mathrm{N}$ stretching) and a broadened shallow peak of N-H stretching shifting to $3396 \mathrm{~cm}^{-1}$ instead of $3282 \mathrm{~cm}^{-1}$. The IR spectra of D-tartaric acid shown in Fig. $5 \mathrm{~b}$ demonstrated the characteristic carbonyl group $\mathrm{C}=\mathrm{O}$ stretching of tartaric acid at $1725 \mathrm{~cm}^{-1}$ and a broad peak between $3200-3400$ indicating $\mathrm{O}-\mathrm{H}$ stretching. In formulations $\mathrm{F} 4-\mathrm{F} 6$, the characteristic peaks of clozapine at 3000-3300 $\mathrm{cm}^{-1}$ (N-H stretching) overlapped with those of tartaric acid (O-H stretching), forming a broad band in this region with short frequencies, which may suggest $\mathrm{H}$-bonding interaction. Similar spectral changes were observed for CZ-oxalic acid co-amorphous dispersions (Fig. 5c). These results along with previous DSC and XRPD data, suggest interaction between clozapine and the carboxylic acids, most probably through $\mathrm{H}$-bonding.

\section{Drug content}

The amount of clozapine incorporated in the co-amorphous dispersion formulations was determined after HPLC analysis of samples and the results showed that the maximum amount of clozapine (85\% of actually weighed amount in formula) was found in F7 while the lowest amount was found into F3 (50 \%). This latter observation with F3 was expected from a previous observation of incomplete interaction of $\mathrm{CZ}$ and citric acid at a 1:2 molar ratio with the remaining crystallinity (XRPD data in Fig. 4a). The content showed intermediate values for formulation F9 (81\%). The results indicated different tendencies or affini- 
A. M. Abdelhaleem Ali et al.: Clozapine-carboxylic acid plasticized co-amorphous dispersions: Preparation, characterization and solution stability evaluation, Acta Pharm. 65 (2015) 133-146.
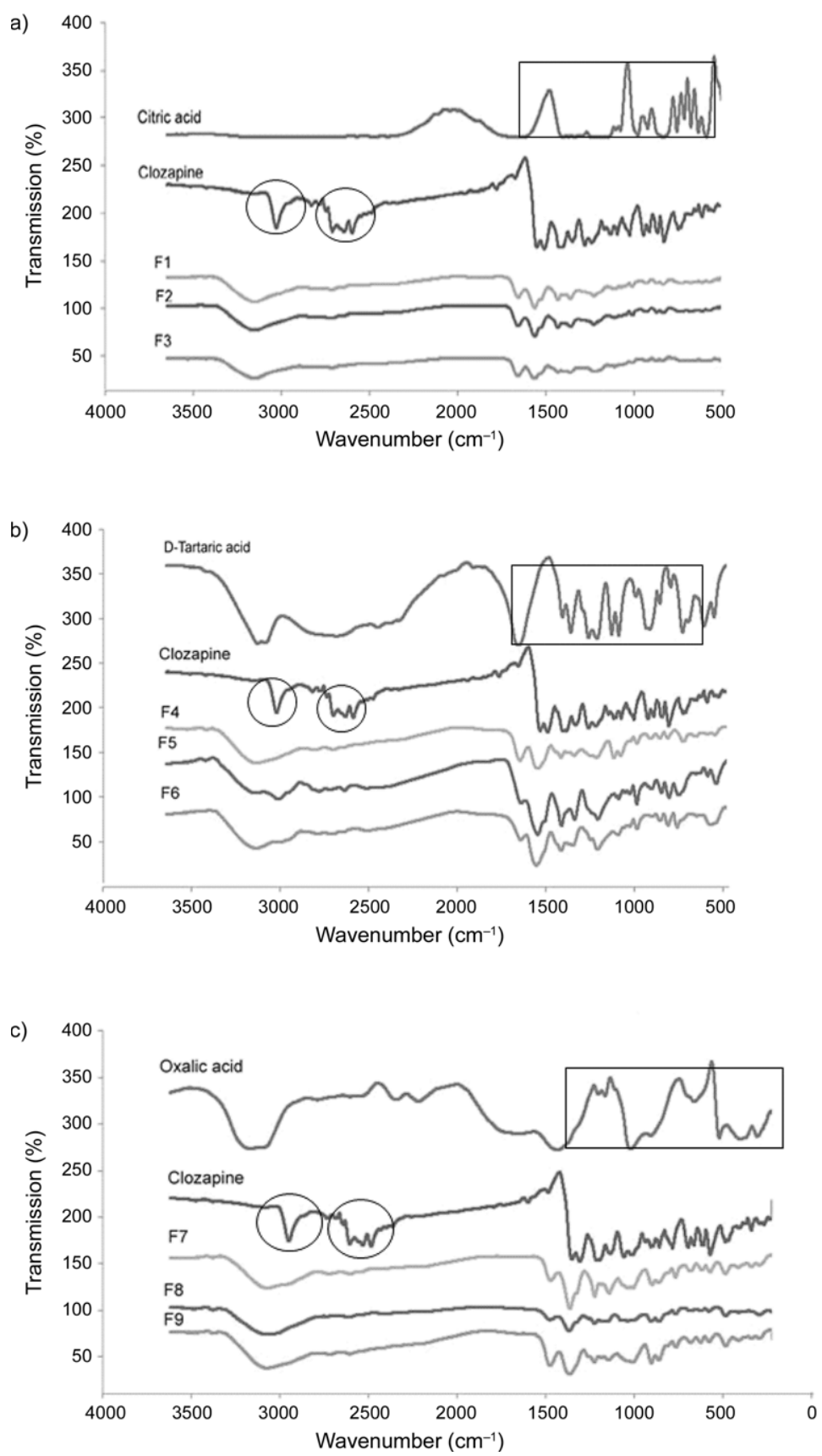

Fig. 5. IR spectra of clozapine co-amorphous dispersions with: a) citric acid, b) D-tartaric acid, and c) oxalic acid. 
ties between clozapine and each of the plasticizing acids towards $\mathrm{H}$-bonding (as demonstrated by the differences in percentage of dissolution), being the highest for oxalic and the lowest for citric and tartaric acid. It also demonstrated that there were optimum ratios of drug-to-plasticizing acid, where complete interaction would predominantly result in a high-drug content amorphous dispersion. This ratio was 1:1 in case of citric and tartaric acids, 1:1 and 1:2 in case of oxalic acid.

\section{In vitro dissolution studies}

The results of percentage dissolution studies (Fig. 6) performed for the prepared coamorphous dispersion formulations indicated higher percentage dissolution of clozapine from compressed tablets $(n=3)$ containing a co-amorphous dispersion compared to those containing the parent crystalline pure drug. Formulation F6 containing CZ-tartaric acid in a 1:2 ratio demonstrated the highest release ( $86.9 \%$ in $10 \mathrm{~min})$. Formulations F2, F4, F6, F7 and F8 released more than $90 \%$ of clozapine within the first $20 \mathrm{~min}$ (see Table II). Formulations F3, F5 and F9 demonstrated intermediate release values and similar profiles. These results indicate that amorphization of clozapine using CAPs led to the formation of highly dissolving dispersions that can be formulated into instantly dissolving dosage forms such as sublingual and orodispersible tablets.

\section{Solution stability}

The solution stability data suggest that the plasticizing acids had different ability to form stable solutions from plasticized co-amorphous dispersions (i.e., the ratio and type of the acid directly affected the extent of formed amorphous clozapine). Higher stability could be obtained from tartaric and citric acid followed by oxalic acid. Separation of very fine particles was exhibited by F8 and, to a lesser extent, by F7. This behavior might be attributed to different solubility of the two separate amorphous components in the mixture

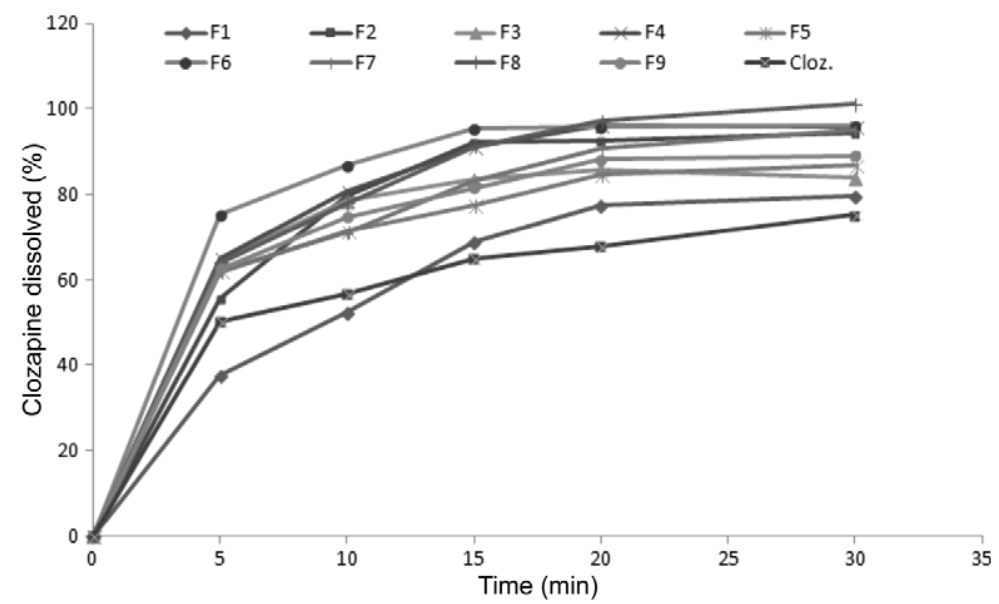

Fig. 6. Dissolution profiles of clozapine from different co-amorphous dispersions (F1-F9) compared to pure clozapine. 
A. M. Abdelhaleem Ali et al.: Clozapine-carboxylic acid plasticized co-amorphous dispersions: Preparation, characterization and solution stability evaluation, Acta Pharm. 65 (2015) 133-146.

(93.2 \% in dissolved state for F7 and $96.5 \%$ in case of F8). Other solutions showed no signs of visual separation or precipitation of particles. HPLC analyses of stored solutions indicated that the smallest percentage of detected drug in solution was observed for formulation F1, whilst the maximum level was demonstrated by F2 (CZ-citric 1:1.5) and F5 (CZtartaric 1:1.5), which showed $100 \%$ of the drug remaining in solution. Formulations F3, F6, F7, F8 and F9 showed more than $90 \%$ of the drug remaining at the end of the storage period of two weeks at $40{ }^{\circ} \mathrm{C}$ and $75 \% \mathrm{RH}$ (see Table II).

\section{CONCLUSIONS}

The above findings indicate that rapid solvent evaporation under vacuum is an excellent method for preparation of clozapine-CAPs co-amorphous dispersions. Carboxylic acids enabled formation of new phases via H-bonding interactions and lowering of the drug glass transition. This facilitated conversion of crystalline clozapine to the more flexible co-amorphous mixture characterized by maximum drug solubility and percentage dissolution. Therefore, co-amorphous dispersions can be considered a valuable solution for drugs having poor water solubility. Clozapine co-amorphous dispersions formed between clozapine and tartaric acid showed the highest percentage dissolution, followed by oxalic and citric acid. However, citric and tartaric acid demonstrated the highest chances for stable co-amorphous dispersions with clozapine at a 1:1.5 molar ratio. Based on these findings, selected carboxylic acids, at specific molar ratios, can be used effectively to formulate stable co-amorphous dispersions with high dissolution properties from poorly soluble crystalline drugs such as clozapine.

Acknowledgements. - The authors acknwolege the research deanship of Taif University, KSA for partial funding of this research. The authors of this research article thank the Egyptian Pharmaceutical Industries Company (EPICO), Cairo, Egypt, for their gift of clozapine. Special thanks are directed to the engineers working at the National Institute of Metals, Cairo, Egypt, for their help with the XRPD and DSC.

\section{REFERENCES}

1. N. Y. Hasan, M. A. Elkawy, B. E. Elzeany and N. E. Wagieh, Stability indicating methods for the determination of clozapine, J. Pharm. Biomed. Anal. 30 (2002) 35-47; DOI: 10.1016/S0731-7085(02) 00125-5.

2. M. Ackenheil, Clozapine pharmacokinetic investigations and biochemical effects in man, Psychopharmacology 99 (1989) 32-37; DOI: 10.1007/bf00442556.

3. A. A. Ambike, K. Mahadik and A. Paradkar, Spray-dried amorphous solid dispersions of simvastatin, a low Tg drug: in vitro and in vivo evaluations, Pharm. Res. 22 (2005) 990-998; DOI: 10.1007/ s11095-005-4594-z.

4. M. Kluge, A. Schuld, A. Schacht, H. Himmerich, M. A. Dalal, P. M. Wehmeier, D. Hinze-Selch, T. Kraus, R. W. Dittmann and T. Pollmcher, Effects of clozapine and olanzapine on cytokine systems are closely linked to weight gain and drug-induced fever, Psychoneuroendocrinology 34 (2009) 118128; DOI: 10.1016/j.psyneuen.2008.08.016.

5. D. Douroumis, Orally disintegrating dosage forms and taste-masking technologies, Expert Opin. Drug Delivery. 8 (2010) 665-675; DOI: 10.1517/17425247.2011.566553. 
A. M. Abdelhaleem Ali et al.: Clozapine-carboxylic acid plasticized co-amorphous dispersions: Preparation, characterization and solution stability evaluation, Acta Pharm. 65 (2015) 133-146.

6. V. Venkateswarlu and K. Manjunath, Preparation, characterization and in vitro release kinetics of clozapine solid lipid nanoparticles, J. Control. Release 95 (2004) 627-638; DOI: 10.1016/j.jconrel.2004.01.005.

7. S. A. Agnihotri and T. M. Aminabhavi, Controlled release of clozapine through chitosan microparticles prepared by a novel method, J. Control. Release 96 (2004) 245-259; DOI: 10.1016/j.jconrel.2004.01.025.

8. T. Vasconcelos, B. Sarmento and P. Costa, Solid dispersions as strategy to improve oral bioavailability of poor water soluble drugs, Drug Discov. Today 12 (2007) 1068-1075; DOI: 10.1016/j. drudis.2007.09.005.

9. O. Almarsson and M. J. Zaworotko, Crystal engineering of the composition of pharmaceutical phases. Do pharmaceutical co-crystals represent a new path to improved medicines?, Chem. Commun. 17 (2004) 1889-1896; DOI: 10.1039/B402150A.

10. K. K. Arora and M. J. Zaworotko, Pharmaceutical co-crystals: A new Opportunity In Pharmaceutical Science for a Long-known but Little Studied Class of Compounds, in Polymorphism in Pharmaceutical Solids (Ed. H. G. Brittain), $2^{\text {nd }}$ ed., Informa Healthcare, London 2009, pp. 281-313.

11. K. J. Crowley and G. Zografi, Cryogenic grinding of indomethacin polymorphs and solvates: assessment of amorphous phase formation and amorphous phase physical stability, J. Pharm. Sci. 91 (2002) 492-507; DOI: 10.1002/jps.10028.

12. E. Gagniere, D. Mangin, S. Veesler and F. Puel, Co-crystallization in Solution and Scale Up Issues, in Pharmaceutical Salts and Co-crystals (Eds. J. Wouters, L. Quere and D. E. Thurston), $1^{\text {st }}$ ed., Royal Society of Chemistry, London 2011, pp. 188-208.

13. N. Blagden, M. de Matas, P. T. Gavan and P. York, Crystal engineering of active pharmaceutical ingredients to improve solubility and dissolution rates, Adv. Drug Deliv. Rev. 59 (2007) 617-630; DOI: 10.1016/j.addr.2007.05.011.

14. K. Lobmann, H. Grohganz, R. Laitinen, C. Strachan and T. Rades, Amino acids as co-amorphous stabilizers for poorly water soluble drugs-Part 1: Preparation, stability and dissolution enhancement, Eur. J. Pharm. Biopharm. 85 (2013) 873-881; DOI: 10.1016/j.ejpb.2013.03.014.

15. Y. Gao, J. Liao, X. Qi and J. Zhang, Coamorphous repaglinide-saccharin with enhanced dissolution, Int. J. Pharm. 450 (2013) 290-295; DOI: 10.1016/j.ijpharm.2013.04.032.

16. A. Shayanfar, H. Ghavimi, H. Hamishekar and A. Jouyban, Coamorphous atorvastatin calcium to improve its physicochemical and pharmacokinetic properties, J. Pharm. Sci. 16 (2013) 577-587.

17. A. Lemmerer, J. Bernstein, and V. Kahlenberg, Hydrogen bonding patterns of the co-crystal containing the pharmaceutically active ingredient isoniazid and terephthalic acid, J. Chem. Crystallogr. 41 (2011) 991-997; DOI: 10.1007/s10870-011-0031-9.

18. M. A. Elbagerma, H. G. M. Edwards, T. Munshi and I. J. Scowen, Identification of a new co-crystal of salicylic acid and benzamide of pharmaceutical relevance, Anal. Bioanal. Chem. 397 (2010) 137146; DOI: 10.1007/s00216-009-3375-7.

19. B. C. Hancock and M. Parks, What is the true solubility advantage for amorphous pharmaceuticals?, Pharm. Res. 17 (2000) 397-404; DOI: 10.1023/a:1007516718048.

20. S. U. Schilling, C. D. Bruce, N. H. Shah, A.W. Malick and J. W. McGinity, Citric acid monohydrate as a release-modifying agent in melt extruded matrix tablets, Int. J. Pharm. 361 (2008) 158-168; DOI: 10.1016/j.ijpharm.2008.05.035.

21. D. R. Weyna, T. Shattock, P. Vishweshwar and M. J. Zaworotko, Synthesis and structural characterization of cocrystals and pharmaceutical cocrystals: mechanochemistry vs slow evaporation from solution, Cryst. Growth Des. 9 (2009) 1106-1123; DOI: 10.1021/cg800936d.

22. A. Newman, D. Engers, S. Bates, I. Ivanisevic, R. C. Kelly and G. Zografi, Characterization of amorphous API: Polymer mixtures using X-ray powder diffraction, J. Pharm. Sci. 97 (2008) 48404856; DOI: 10.1002/jps.21352. 
A. M. Abdelhaleem Ali et al.: Clozapine-carboxylic acid plasticized co-amorphous dispersions: Preparation, characterization and solution stability evaluation, Acta Pharm. 65 (2015) 133-146.

23. C. Guitton, J. M. Kinowski, R. Aznar and F. O. Bressolle, Determination of clozapine and its major metabolites in human plasma and red blood cells by high-performance liquid chromatography with ultraviolet absorbance detection, J. Chromatogr. 690 (1997) 211-222; DOI: 10.1016/s0378-4347 (96)00362-3.

24. M. Vasanthavada, W-Q. T. Tong, Y. Joshi and M. S. Kislalioglu, Phase behavior of amorphous molecular dispersions II: Role of hydrogen bonding in solid solubility and phase separation kinetics, Pharm. Res. 22 (2005) 440-448; DOI: 10.1007/s11095-004-1882-y.

25. Q. Lu and G. Zografi, Phase behavior of binary and ternary amorphous mixtures containing indomethacin, citric acid and PVP, Pharm. Res. 15 (1998) 1202-1206; DOI: 10.1023/a:1011983606606.

26. H. Bley, B. Fussnegger and R. Bodmeier, Characterization and stability of solid dispersions based on PEG/polymer blends, Int. J. Pharm. 390 (2010) 165-173; DOI: 10.1016/j.ijpharm.2010.01.039.

27. J. E. Patterson, M. B. James, A. H. Forster, R.W. Lancaster, J. M. Butler and T. Rades, Preparation of glass solutions of three poorly water soluble drugs by spray drying, melt extrusion and ball milling, Int. J. Pharm. 336 (2007) 22-34; DOI: 10.1016/j.ijpharm.2006.11.030. 